\title{
Research on the Maximal Bearing Capacity Calculation of a New Double Ring Reducer Based on MATLAB
}

\author{
Qiang $\mathrm{Xu}^{*}, 1, \mathrm{Qi}-$ sheng $\mathrm{Xu}^{1}$ and Dao-Yi Xu${ }^{2}$ \\ ${ }^{1}$ Department of Mechanical Engineering, Hefei University, Hefei, 230601, China \\ ${ }^{2}$ Anhui Xiao Xiao Science and Technology Limited Company, Jixi 510660, China
}

\begin{abstract}
The bearing capacity of a new double ring reducer increases with the increase of load because of the elastic deformation of the gear tooth. In order to solve the problem of its bearing capacity quantificationally, the concept of the maximal bearing capacity is put forward. Starting with that the single tooth bending stress is up to the bending fatigue strength, a mathematical model to determine the normal backlash of the gear teeth has been established, the maximal deformation of the single tooth has been determined. The mathematical relationships have also been setup between the normal backlashes of the tooth pairs, the maximal deformation and number of contact points, a corresponding MATLAB program is designed. The maximal bearing capacity of the reducer has been estimated through examples and proved by experiment. The results show that the calculation method is more effective and fully considers the factors that the elastic deformation of the gear tooth can increases its bearing capacity, so the structure of the reducer is more compact, which establishes the theory foundation for designing the reducer.
\end{abstract}

Keywords: Double ring reducer, engaging point, maximal deformation, normal backlash.

\section{INTRODUCTION}

For a three-ring reducer and a four-ring reducer, the machining precision is hard to be guaranteed because three or four-phase drive ring plates are at 120 or 90 degree angles from each other, which causes the plates interfere each other, resulting in vibration, noise and heating. A new double ring reducer (Patent China, ZL01206843.8) was invented to overcome the shortcomings of the three or four ring reducer and carry forward their advantages. A new double ring reducer is widely applied in mine, metallurgy, chemical industry, aviation and space flight etc. because it is of many advantages, such as with compact structure, bigger reduction ratio, easy insuring machining precisions, less force of planetary gear bearings $[1,2]$.

A new double ring reducer is the special planetary transmission mechanism in which internal gears do translation, and make the external gear rotate. In transferring loads, the tooth deformation is more than clearance between some teeth profiles, the untouched teeth are made to mesh, and improving greatly the bearing capacity of the mechanism. Many Chinese scholars have done many researches on the theoretical calculation of the gap of teeth of internal matins gears, and the relation between contact tooth pair number and load. The bigger the load transmitted, the more the number of teeth pairs mating simultaneously. When the strength is checked, although the concept of the elastic mesh effective coefficient is introduced, it has brought the confusions to designers that the coefficient is variable [3-6]. This paper presents the concepts of the maximal bearing capacity of the gear reducer. The calculation of the clearance between the tooth profiles is taken as starting, the maximal allowed deformation of single tooth is analyzed, and the maximal bearing capacity of the reducer is calculated. If the load of the reducer is less than the maximal bearing capacity of the reducer, it is thought that the reducer can meet the demand of bending fatigue strength. The method improves design efficiency, reduces the cost, and fully considers that the elastic deformation has influence on increasing the bearing capacity.

\section{THE ESTABLISHMENT OF MATHEMATICAL MODELS OF THE NORMAL BACKLASH OF THE TEETH PAIRES}

The structure diagram of a new double ring reducer is shown in Fig. (1); the high-speed level is composed of a pair of helical cylinder gears a b, the low-speed level is a planetary transmission with small tooth number difference. $\mathrm{H}$ is an active crankshaft, $\mathrm{Z}_{2}$ is an inner planetary gear, and $Z_{1}$ is an external gear. The inner planetary gears do translation by work principles of two-crank mechanism, a rotation motion is input from the gear a, the motion is output from the external gear $Z_{1}$ by bigger reduction ratio.

For the special internal gear pairs of the double ring reducer with small teeth difference, under the action of the external load $F_{n}$, because of elastic deformation of gear teeth, there are several simultaneously meshing points of $\mathrm{K}_{0}, \mathrm{~K}_{1}$, $\mathrm{K}_{2} \ldots \ldots . \mathrm{K}_{\mathrm{i}}$, the relation between the loads $\mathrm{F}_{\mathrm{ni}}$ withstood by each pair of teeth and the normal backlash Jni of the tooth pair is as follows [4]: 


$$
\left\{\begin{array}{l}
\mathrm{F}_{\mathrm{n} 0}=\mathrm{C}_{\mathrm{n}} \delta_{\mathrm{n} 0} \\
\mathrm{~F}_{\mathrm{ni}}=\mathrm{C}_{\mathrm{n}}\left(\delta_{\mathrm{n} 0}-\mathrm{j}_{\mathrm{ni}}\right) \\
\mathrm{Z}_{\mathrm{H}}=\mathrm{i}+1 \\
\mathrm{~F}_{\mathrm{n}}=\sum_{\mathrm{i}=0}^{\mathrm{i}} \mathrm{F}_{\mathrm{ni}}
\end{array}\right.
$$

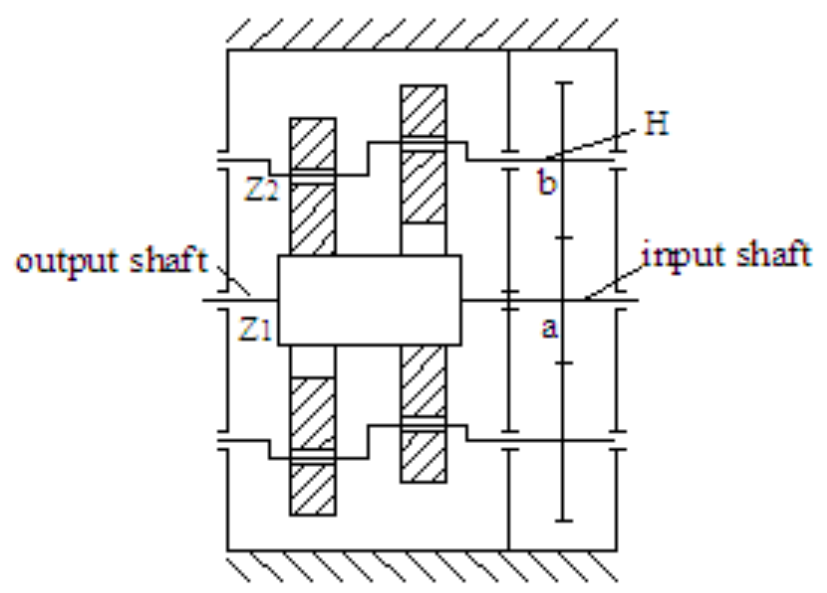

Fig. (1). The structure diagram of a new double ring reducer.

Fig. (2) describes the backlash of the tooth pairs before they mesh. $\mathrm{B}_{1} \mathrm{~B}_{2}$ is the actual meshing line. The center $\mathrm{O}_{1}$ of external gear is the origin of external gear coordinate system, the center $\mathrm{O}_{2}$ of internal gear is the origin of internal gear coordinate system. When the extended lines of the internal and external tooth profiles mesh at the point $\mathrm{K}_{\mathrm{i}}^{\prime}$ (virtual points and their normal backlash before meshing engaging point), the distance between the tooth top $\mathrm{C}$ of external gear and the tooth profile of internal gear is the shortest. While the engaging point $\mathrm{K}_{0}$ on the meshing line is transferring load, the gear teeth occur deformation, the internal gear is forced to rotate angle $\phi$ additionally, the point D of the internal tooth profile contacts the tooth tip $\mathrm{C}$ of the external gear, which can be the contact point $\mathrm{K}_{\mathrm{i}}$. If $\alpha_{a 1}$ is the tip circle's pressure angle of external gear, $\phi_{1}$ (the angle $\mathrm{PO}_{1} \mathrm{C}$ ) is [6].

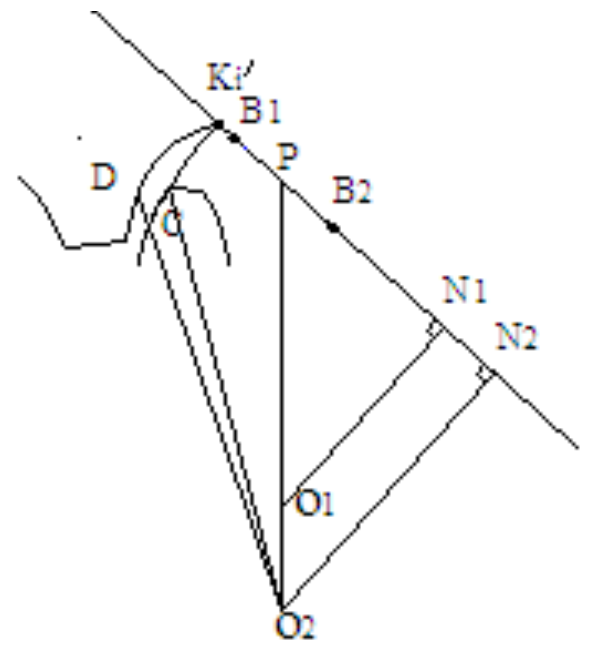

Fig. (2). The relationship between the positions of virtual contact. $\phi_{1}=\operatorname{inv} \alpha_{a 1}-\frac{K_{i}^{\prime} N_{1}}{r_{b 1}}+\alpha^{\prime}$

Here $\alpha^{\prime}$ is the actual engagement angle of internal gear pair with small teeth difference.

The distance between the point $\mathrm{C}$ and the center $\mathrm{O}_{1}$ of the external gear is the addendum circle radius $r_{a 1}$, the coordinates of the point $\mathrm{C}$ in the coordinate system of the external gear are

$\mathrm{x}_{c 1}=\mathrm{r}_{a 1} \sin \phi_{1}$
$y_{c 1}=\mathrm{r}_{a 1} \cos \phi_{1}$

If $a^{\prime}$ is the actual centre distance of internal gear pairs with small teeth difference, the coordinates of the point $\mathrm{C}$ in the coordinate system of the internal gear are

$$
\begin{aligned}
& \mathrm{x}_{c 2}=\mathrm{x}_{c 1} \\
& y_{c 2}=\mathrm{y}_{c 1}+a^{\prime}
\end{aligned}
$$

As a result, the center distance between the point $\mathrm{C}$ and the point $\mathrm{O}_{2}$ is

$r_{c 2}=\sqrt{x_{c 2}{ }^{2}+y_{c 2}^{2}}$

The distance $\mathrm{r}_{\mathrm{D} 2}$ between the point $\mathrm{D}$ of the internal tooth profile and the centre $\mathrm{O}_{2}$ is also $\mathrm{r}_{\mathrm{C} 2}$, namely the pressure angle of the point $\mathrm{D}$ is as follows

$\alpha_{\mathrm{D} 2}=\arccos \left(\frac{\mathrm{r}_{b 2}}{r_{D 2}}\right)$

$\phi_{2}$ is the angle $\mathrm{PO}_{2} \mathrm{D}$, So [6]

$\phi_{2}=\operatorname{inv} \alpha_{\mathrm{D} 2}-\frac{K_{\mathrm{i}}^{\prime} N_{2}}{r_{b 2}}+\alpha^{\prime}$

The coordinate of the point $\mathrm{D}$ in the coordinate system of the internal gear is

$\mathrm{x}_{\mathrm{D} 2}=\mathrm{r}_{\mathrm{D} 2} \sin \phi_{2}$
$\mathrm{y}_{D 2}=\mathrm{r}_{\mathrm{D} 2} \cos \phi_{2}$

The distance between the point $\mathrm{D}$ and the point $\mathrm{C}$, namely the normal backlash $\mathrm{J}_{\mathrm{ni}}$ of the engaging point is as follows:

$\overline{\mathrm{CD}}=\sqrt{\left(\mathrm{x}_{c 2}-x_{D 2}\right)^{2}+\left(y_{c 2}-y_{D 2}\right)^{2}}$

Fig. (3) describes the backlash of the tooth pairs after their meshing. $\mathrm{B}_{1} \mathrm{~B}_{2}$ is the actual meshing line. When the extended lines of the internal or external tooth profiles mesh at the point $\mathrm{K}_{i}^{\prime}$ (virtual engaging point), the distance between the tooth top $\mathrm{C}$ of internal gear and the tooth profile of external gear is points and their normal backlash after meshing the shortest. While the engaging point $\mathrm{K}_{0}$ on the meshing line is transferring load, the gear teeth occur deformation, the internal gear is forced to rotate angle $\phi$ additionally, the tooth tip $\mathrm{C}$ of the internal gear contacts the point $\mathrm{D}$ of the external tooth profile, which can be the 
contact point $\mathrm{K}_{\mathrm{i}}$. If $\alpha_{a 2}$ is the tip circle's pressure angle of internal gear, $\phi_{2}$ (the angle $\mathrm{PO}_{2} \mathrm{C}$ ) is [6]

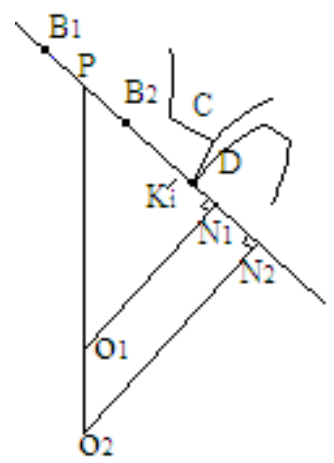

Fig. (3). The relationship between the positions of virtual contact.

$\phi_{2}=\operatorname{inv} \alpha_{a 2}-\frac{K_{\mathrm{i}}^{\prime} N_{2}}{r_{b 2}}+\alpha^{\prime}$

Here $\alpha^{\prime}$ is the actual engagement angle of internal gear pair of less tooth difference.

The distance between the point $\mathrm{C}$ and the center $\mathrm{O}_{2}$ of the internal gear is the addendum circle radius $r_{a 2}$, the coordinates of the point $\mathrm{C}$ in the coordinate system of the internal gear are

$\mathrm{x}_{c 2}=\mathrm{r}_{a 2} \sin \phi_{2}$

$y_{c 2}=\mathrm{r}_{a 2} \cos \phi_{2}$

If $a^{\prime}$ is the actual centre distance of internal gear pairs with small teeth difference, the coordinates of the point $\mathrm{C}$ in the coordinate system of the external gear are

$\mathrm{X}_{c 1}=\mathrm{X}_{c 2}$

$y_{c 1}=\mathrm{y}_{c 2}-a^{\prime}$

As a result, the center distance between the point $\mathrm{C}$ and the point $\mathrm{O}_{1}$ is

$r_{c 1}=\sqrt{x_{c 1}^{2}+y_{c 1}^{2}}$

The distance $r_{D 1}$ between the point $\mathrm{D}$ of the external tooth profile and the centre $\mathrm{O}_{1}$ also is $\mathrm{r}_{\mathrm{Cl}}$, namely the pressure angle of the point $\mathrm{D}$ is as follows:

$\alpha_{\mathrm{D} 1}=\arccos \left(\frac{\mathrm{r}_{b 1}}{r_{D 1}}\right)$

$\phi_{1}$ is the angle $\mathrm{PO}_{1} \mathrm{D}$, So [7]

$\phi_{1}=\operatorname{inv} \alpha_{\mathrm{D} 1}-\frac{K_{\mathrm{i}}^{\prime} N_{1}}{r_{b 1}}+\alpha^{\prime}$

The coordinate of the point $\mathrm{D}$ in the coordinate system of the external gear is

$\mathrm{x}_{\mathrm{D} 2}=\mathrm{r}_{\mathrm{D} 2} \sin \phi_{1}$

$\mathrm{y}_{D 2}=\mathrm{r}_{\mathrm{D} 2} \cos \phi_{1}$
The distance between the point $\mathrm{D}$ and the point $\mathrm{C}$, namely the normal backlash Jni of the engaging point $\mathrm{Ki}$ is as follows:

$\overline{\mathrm{CD}}=\sqrt{\left(\mathrm{x}_{c 1}-x_{D 1}\right)^{2}+\left(y_{c 1}-y_{D 1}\right)^{2}}$

From the above formula, the CD size is related with the position of virtual engaging point $\mathrm{K}_{i}^{\prime}$, the engaging angle $\alpha^{\prime}$, and the addendum circle diameter.

\section{DETERMINATION OF THE MAXINAL DEFORMATION OF THE SINGLE GEAR}

If the transmitting power of a double ring reducer is $\mathrm{P}$, the motor rotating speed $\mathrm{n}_{\mathrm{D}}$, and the transmission ratio $\mathrm{i}$, the torque of the external gear is

$$
\mathrm{T}=9.55 \times 10^{6} \frac{P}{n_{D} i}
$$

If two translational internal gears are considered, the normal force $F_{n}$ on external gear is calculated as

$$
\mathrm{F}_{\mathrm{n}}=\frac{\mathrm{T}}{\mathrm{mZ} \mathrm{Z}_{1} \cos \alpha}
$$

As Fig. (4) shows, the point $B_{1}$ is the starting point of the actual meshing line. At the point $B_{1}$ the tooth root of the translational internal gear and the tooth top of external gear begin to enter into meshing, the point $\mathrm{B}_{2}$ is the point to terminate and withdraw from the meshing line, and $\mathrm{B}_{1} \mathrm{~B}_{2}$ is the actual meshing line. Suppose $\mathrm{K}_{0}$ is any meshing point on $\mathrm{B}_{1} \mathrm{~B}_{2}, \mathrm{~K}_{1}^{\prime}, \mathrm{K}_{2}^{\prime} \ldots \mathrm{K}_{\mathrm{i}}^{\prime}$ are virtual engaging points on the meshing line, the index odd number is the virtual engaging points before entering the actual meshing line, and the index even number is the virtual engaging points after quitting the actual meshing line.

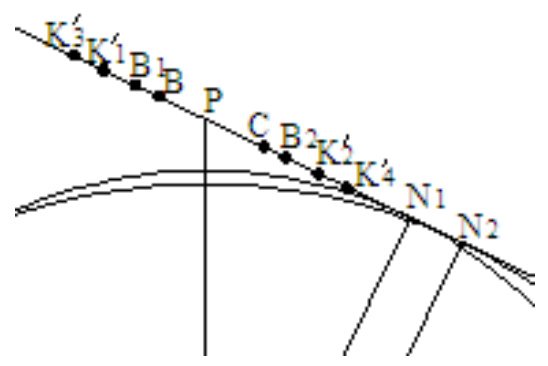

Fig. (4). The name and positions of the different engaging points.

The gear teeth of internal gear pairs with small teeth difference bend in the same direction, the difference among their curvature radiuses are very small. Therefore, soft surface tempering gear is always used. Generally, the touch strength of gear is not calculated, only checking the bending strength [7]. BC is the meshing line of single pair of gears, its upper or lower bound points are the load action point producing maximal bending moment, the maximal bending deformation generate at same time. Suppose $\mathrm{K}$ is loading coefficient, $Y_{F}$ is the tooth form factor, $Y_{S}$ is stress correction coefficient, and $\mathrm{Y} \varepsilon$ is contact ratio coefficient. When the tooth root bears the allowable bending stress $\left[\sigma_{\mathrm{F}}\right]$, the maximal affordable normal force is [8] 


$$
\mathrm{F}_{0 \max }=\frac{\mathrm{bm}\left[\sigma_{\mathrm{F}}\right]}{\mathrm{KY}_{\mathrm{F}} \mathrm{Y}_{\mathrm{S}} \mathrm{Y}_{\varepsilon}}
$$

and the allowable bending stress is

$$
\left[\sigma_{\mathrm{F}}\right]=\frac{\sigma_{\mathrm{Flim}} \mathrm{Y}_{\mathrm{N}}}{\mathrm{S}_{\mathrm{F}}}
$$

Here $\sigma_{\text {Flim }}$ is the bending fatigue strength of the tooth root of the experiment gear. $\mathrm{Y}_{\mathrm{N}}$ is the life coefficient for computing the bending strength. $\mathrm{S}_{\mathrm{F}}$ is the safety factor for computing the bending strength.

The value of $\mathrm{F}_{0 \max }$ is related to the points $\mathrm{B}, \mathrm{C}$, it is primarily to due to the different allowable bending stresses $\left[\sigma_{\mathrm{F}}\right]$ and the different tooth form factor $\mathrm{Y}_{\mathrm{F}}$. Under the effect of $\mathrm{F}_{0 \max }$, the gear tooth will produce a more normal deformation. It includes contact deformation, bending deformation and shear deformation of the gear tooth, and the deformation of the gear tooth root. The meshing stiffness of the gear differs depending on the position of engaging points. To simply the problem, the average meshing stiffness of the gear tooth is regarded as the meshing stiffness. From Ref. [9], the maximal normal elastic deformation is

$$
\delta_{\mathrm{n} 0}=\frac{\mathrm{F}_{0 \max }}{\mathrm{bC}_{\mathrm{r}}}
$$

Here $\mathrm{Cr}$ is the average meshing stiffness of the gear tooth. For the meshing gear subjected to the medium load, it takes approximately $20 \mathrm{~N} / \mathrm{mm} \cdot \mathrm{um}$.

\section{CALCULATION OF THE MAXIMAL BEARING CAPACITY}

If the tooth profile coefficient of the external gear $Z_{1}$ is less than that of the internal gear $Z_{2}$, the external gear tooth at the point $B$ is easier to produce fatigue failure. Therefore, while the gear teeth mesh at the point $\mathrm{B}$, and the stress of the external gear tooth root reaches flexural ultimate strength, the deformation of it is also the biggest. Conversely, at the point $\mathrm{C}$, for the inner gear tooth, we can draw a conclusion that is coincident with the above conclusion. As Fig. (4) shows, $\mathrm{B}_{1} \mathrm{~B}_{2}$ is the actual meshing line; $\mathrm{BC}$ is the meshing line of single gear pair, $\mathrm{B}_{1} \mathrm{~B}$ and $\mathrm{CB}_{2}$ is that of the double gear pairs. So

$$
\left\{\begin{array}{l}
B_{1} B_{2}=\frac{1}{2} \mathrm{~m} \cos \alpha\left[Z_{1}\left(\tan \alpha_{a 1}-\tan \alpha^{\prime}\right)+Z_{2}\left(\tan \alpha^{\prime}-\tan \alpha_{a 2}\right)\right] \\
\mathrm{N}_{1} \mathrm{~N}_{2}=\frac{1}{2} \mathrm{~m}\left(Z_{2}-Z_{1}\right) \cos \alpha \tan \alpha^{\prime}
\end{array}\right.
$$

If $\mathrm{P}_{\mathrm{b}}$ is a pitch, the length of the meshing line of the double gear pairs is as follows:

$$
\mathrm{B}_{1} \mathrm{~B}=\mathrm{CB}_{2}=(\varepsilon-1) \mathrm{P}_{b}
$$

The meshing line length of single gear pair is

$$
\mathrm{BC}=(2-\varepsilon) \mathrm{P}_{b}
$$

$$
\begin{aligned}
\mathrm{B}_{1} N_{1} & =B_{1} N_{2}-N_{1} N_{2} \\
& =r_{a 2} \sin \alpha_{a 2}-\frac{1}{2} m\left(Z_{2}-Z_{1}\right) \cos \alpha \tan \alpha^{\prime}
\end{aligned}
$$

So,

$\mathrm{BN}_{1}=\mathrm{B}_{1} \mathrm{~N}_{1}+\mathrm{BB}_{1}$

In order to meet various restrictions, modified gears must be adopted for the double ring reducer. The engagement angle and the total modification coefficient are as follows

$\alpha^{\prime}=\arccos \left(\frac{a}{a^{\prime}} \cos \alpha\right)$

$x_{\Sigma}=x_{2}-x_{1}=\frac{z_{2}-z_{1}}{2 \tan \alpha}\left(i n v \alpha^{\prime}-i n v \alpha\right)$

Here $a$ is the standard centre distance, $a^{\prime}$ is the actual centre distance.

For the internal gear pairs with small teeth difference, the actual engagement angle is greater than the standard pressure angle as the actual centre distance is greater than the standard centre distance.

While the gear teeth mesh at the point $\mathrm{B}$, the distance between adjacent engaging points is $\pi \mathrm{m} \cos \alpha$. According to the formula (1), it is determined that how many tooth profiles mesh, the maximal carrying forces at different meshing points are calculated and compared, therefore the maximal carrying capacity of the double ring reducer is computed, the concrete computation steps are given as follows:

1) Input the calculation parameter of the double ring reducer: module $\mathrm{m}$, teeth numbers $\mathrm{Z}_{1}$ and $\mathrm{Z}_{2}$, the tooth width $\mathrm{b}$, addendum coefficients $\mathrm{X}_{1}$ and $\mathrm{X}_{2}$, other parameters related to bending strength of gear.

2) Compute the engagement angle $a^{\prime}$, the contact ratio $\varepsilon$, the pressure angle of addendum circle, the actual centre distance $a^{\prime}$, and the values of $\mathrm{B}_{1} \mathrm{~B}_{2}, \mathrm{BN}_{1}, \mathrm{~N}_{1} \mathrm{~N}_{2}$, $\mathrm{F}_{0 \max }$ and $\delta_{\mathrm{n} 0}$, order $\mathrm{i}=1$.

3) Judge whether $i$ is an odd number or an even number. If $\mathrm{i}$ is an odd number, $\mathrm{K}_{\mathrm{i}}^{\prime} \mathrm{N}_{1}$ and $\mathrm{K}_{\mathrm{i}}^{\prime} \mathrm{N}_{2}$ are

$$
\begin{aligned}
& \mathrm{K}_{\mathrm{i}}^{\prime} \mathrm{N}_{1}=\mathrm{BN}_{1}+\left(\frac{\mathrm{i}-1}{2}+1\right) \mathrm{P}_{b} \\
& \mathrm{~K}_{\mathrm{i}}^{\prime} \mathrm{N}_{2}=\mathrm{K}_{i}^{\prime} \mathrm{N}_{1}+\mathrm{N}_{1} \mathrm{~N}_{2}
\end{aligned}
$$

If $\mathrm{i}$ is an even number, $\mathrm{K}_{\mathrm{i}}^{\prime} \mathrm{N}_{1}$ and $\mathrm{K}_{\mathrm{i}}^{\prime} \mathrm{N}_{2}$ are

$$
\begin{aligned}
& \mathrm{K}_{\mathrm{i}}^{\prime} \mathrm{N}_{1}=\mathrm{BN}_{1}-\left(\frac{\mathrm{i}-2}{2}+1\right) \mathrm{P}_{b} \\
& \mathrm{~K}_{\mathrm{i}}^{\prime} \mathrm{N}_{2}=\mathrm{K}_{i}^{\prime} \mathrm{N}_{1}+\mathrm{N}_{1} \mathrm{~N}_{2}
\end{aligned}
$$

If $\mathrm{K}_{\mathrm{i}}^{\prime} \mathrm{N}_{1}<0$, order $\delta_{\mathrm{n} 0}=\mathrm{J}_{\text {ni-1 }}$, compute $\mathrm{F}_{0 \max }$, switch to step 2.

4) According to formula (2) - formula (16), compute angle $\phi_{1}$, angle $\phi_{2}$, and the minimal tooth profile clearance $J_{\mathrm{ni}}$. 
5) If $\delta_{\mathrm{n} 0}>\mathrm{J}_{\mathrm{ni}}$, compute $\mathrm{F}_{\mathrm{i}}$, order $\mathrm{i}=\mathrm{i}+1$, go to step 3 .

6) Using the formula (1), compute $\mathrm{F}_{0 \max }$, the concrete program flow chart is showed in Fig. (5).

It is necessary to state that virtual engaging point cannot exceeds the limit engaging point, otherwise the interference is produced. Therefore, $\mathrm{K}_{\mathrm{i}}^{\prime} \mathrm{N}_{1}$ must be greater than zero. Meanwhile change $\mathrm{BN}_{1}$ to $\mathrm{CN}_{1}$ or $\mathrm{PN}_{1}$, namely $\mathrm{K}_{\mathrm{i}} \mathrm{N}_{1}$ whose engaging point is at $\mathrm{C}$ or $\mathrm{P}$ can be found. The goal of calculating the force $F_{n \max }$ at $\mathrm{P}$ is to compare it with $\mathrm{F}_{n \max }$ at $\mathrm{B}$ or $\mathrm{C}$ to determine the maximal carrying capacity of the double ring reducer, although its tooth root stress cannot reaches bending fatigue strength.

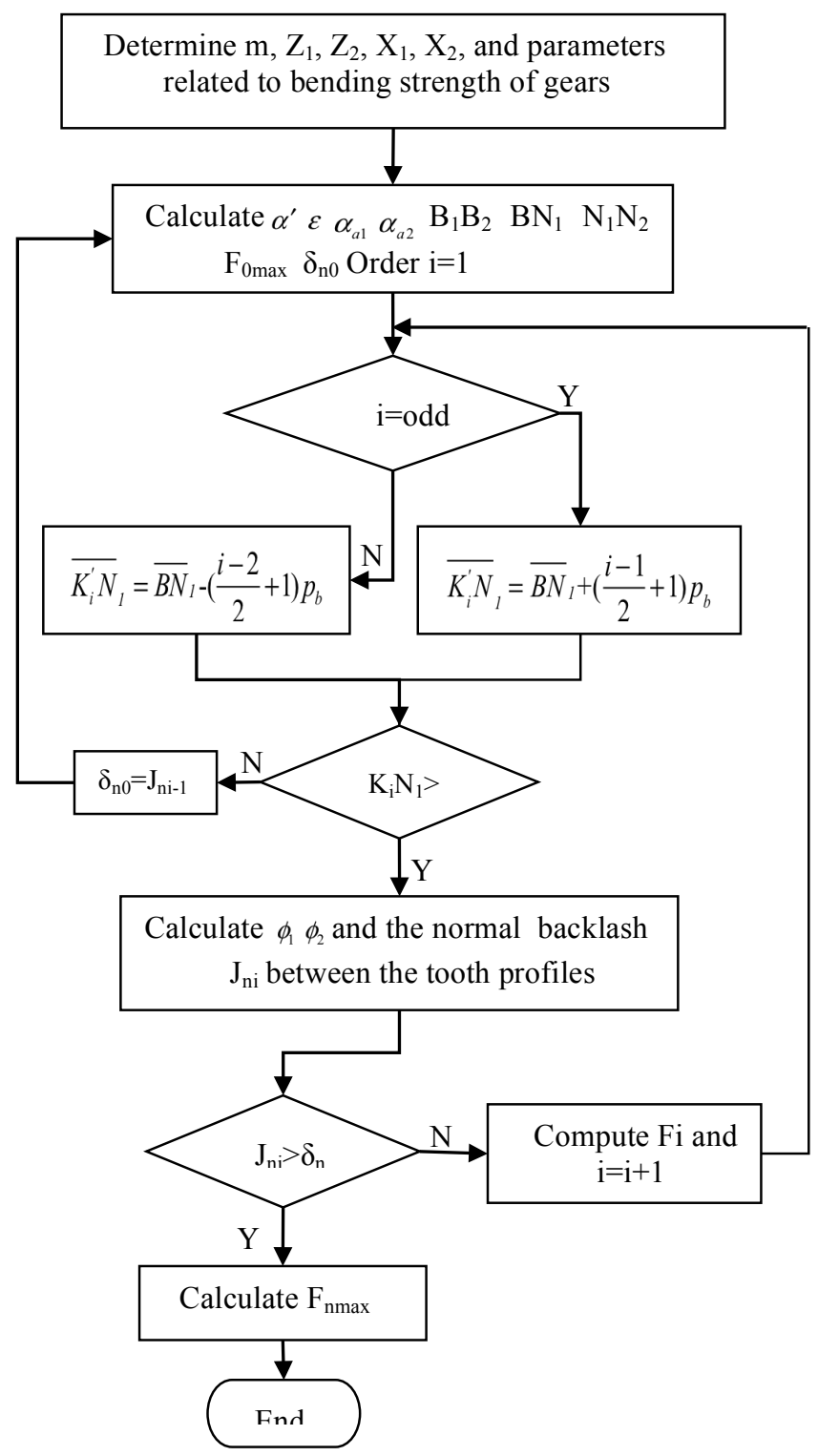

Fig. (5). The program flow block diagram.

\section{ANALYSIS OF THE CACULATION EXAMPLE}

According to the literature [10], the transmission power of the double ring reducer is $5.1 \mathrm{KW}$, the transmission ratio is $1: 43.5$, and the rotating speed of the motor is $1500 \mathrm{rpm}$. The design parameters are the gear modules $m=2$, the teeth of the driven external gear $Z_{1}=56$, the teeth of the driving internal gear $Z_{2}=58$, the gear width $b=95$. The addendum coefficient is 0.7 , the radical clearance coefficient is 0.25 , the modification coefficient of the internal gear $\mathrm{x}_{2}=1.68$, the modification coefficient of the external gear $\mathrm{x}_{1}=1.37$, the actual centre distance $a=2.42$. The teeth of the shaping cutter $\mathrm{Z}_{0}=38$, its addendum coefficient is 1.25 , its modification coefficient is $\mathrm{x}_{0}=0.42$. Materials of internal and external gears are selected from $40 \mathrm{Cr}, 42 \mathrm{Cr} \mathrm{Mu}$ and are quenched. By the design, the material strength of the external gear is close to that of the internal gear, the waste of material is avoided.

Table 1. The maximal bearing capacity in different engaging points.

\begin{tabular}{|c|c|c|c|c|c|c|}
\hline \multirow{2}{*}{$\begin{array}{c}\text { Engaging } \\
\text { Positions }\end{array}$} & \multicolumn{4}{|c|}{ Normal Backlash (um) } & \multirow{2}{*}{$\boldsymbol{\delta}_{\mathbf{n} \mathbf{0}}(\mathbf{u m})$} & \multirow{2}{*}{$\mathbf{F}_{\mathbf{n m a x}}(\mathbf{N})$} \\
\cline { 2 - 6 } & $\mathbf{J}_{\mathbf{3}}$ & $\mathbf{J}_{\mathbf{1}}$ & $\mathbf{J}_{\mathbf{2}}$ & $\mathbf{J}_{\mathbf{4}}$ & & \\
\hline \hline $\mathrm{B}$ & 34.52 & 8.05 & 0 & 10.94 & 4.36 & 16650 \\
\hline $\mathrm{P}$ & 20.61 & 2.05 & 2.12 & 23.33 & 4.36 & 16900 \\
\hline $\mathrm{C}$ & 10.06 & 0 & 8.67 & 40.82 & 4.36 & 16650 \\
\hline
\end{tabular}

While the engaging point is on the point $\mathrm{B}, \mathrm{P}, \mathrm{C}$, the different clearances between tooth pairs and the maximal load-carrying capacities are shown in Table 1.

From above Table 1, we find that the simultaneously meshing teeth pairs are 2 pairs or 3 pairs when the engaging point is on the meshing line of single gear pair. The carrying capacity at the point $\mathrm{P}$ is the biggest, but considering the bending fatigue strength, the allowable maximal carrying capacity of the double ring reducer is $16650 \mathrm{~N}$. In order to transfer the above load, its carrying force is $1322.2 \mathrm{~N}$ according to formula (17) and (18) and is lower than the allowable maximal carrying capacity, and can meet the requirement of design. At the same time, from Table 1, the smaller the distance from the meshing line of single gear pair is, the smaller the value of the minimal clearance of the tooth pair is, the easier is the tooth pairs to cause elastic contact and bear load.

The two double ring reducers are designed according to the above-mentioned design parameters. During the process of design, the fatigue life of the two helical gears $a, b$ and other components is made higher than that of internal gear pairs with few teeth difference intentionally. By means of the open experimental equipment of the reducer assembly, the fatigue test is conduct. The first task is the empty running-in of the prototypes, and then the prototypes work in fatigue and full load. During the process of the fatigue test, the input torque of the reducer is $35.4 \mathrm{Nm}$, and its input speed is $2500 \mathrm{rpm}$, the test results of the assembly are presented in Table 2.

Table 2. Fatigue life test data of double ring reducers.

\begin{tabular}{|c|c|c|c|}
\hline & $\begin{array}{c}\text { Test Time } \\
\text { (Minute) }\end{array}$ & $\begin{array}{c}\text { Recycle Times } \\
\text { (Internal Gear) }\end{array}$ & Failure Mode \\
\hline \hline 001 & 91 & 113750 & The tooth-breaking of gear Z2 \\
\hline 002 & 82 & 102500 & The tooth-breaking of gear Z1 \\
\hline
\end{tabular}


According to the theoretic calculations of this paper, if the reducer retains continuous running over 70 minutes under circumstances of the above-mentioned input torque and speed, the reducer is qualified. If there had not been the multi-tooth mesh effects, the gear tooth should have fractured because the input torque is $284 \%$ higher than the rated torque. The hypothesis does not match the test results; it proves that above-mentioned theory is correct. The test time is larger than the theoretic calculating time and is discrete; this may be caused by using mean value of normal meshing stiffness and the form and position error of gear tooth surface.

Table 3. The effects of the change of centre distance on normal backlash.

\begin{tabular}{|c|c|c|c|c|c|}
\hline \multirow{2}{*}{$\begin{array}{c}\text { Centre Distance } \\
(\mathbf{m m})\end{array}$} & \multicolumn{4}{|c|}{ Normal Backlash (um) } & \multirow{2}{*}{ Fmax (N) } \\
\cline { 2 - 5 } & $\mathbf{J 3}$ & $\mathbf{J 1}$ & $\mathbf{J 2}$ & $\mathbf{J 4}$ & \\
\hline \hline 2.42 & 20.61. & 2.05 & 2.12 & 23.33 & 16900 \\
\hline 2.4 & 19.78 & 1.91 & 1.97 & 22.48 & 17417 \\
\hline
\end{tabular}

Being satisfied with the various limitations, the centre distance is turned to $a=2.4$, the modification coefficient of the internal gear $\times 2=1.528$, the modification coefficient of the external gear $\mathrm{x} 1=1.231$. When the engaging point is on the point $\mathrm{P}$, the comparison of the clearances between tooth pairs and the maximum load-carrying capacity are shown in Table 3.

From above Table 3, if the centre distance decreases, the smaller the clearances between tooth pairs become, the easier is the tooth pairs to cause elastic contact, and the carrying capacity is raised.

\section{CONCLUSION}

Through the above-mentioned analysis, such conditions can be drawn as follows

1) Starting with that the tooth root stress reaches the bending fatigue strength, the mathematical models of relationships among the normal clearance of each tooth pair and the position of virtual engaging point and the maximal carrying capacity is established, the MATLAB program is compiled.

2) Through MATLAB program, it is easy to estimate the maximal carrying capacity of the double ring reducer. The design efficiency is increased greatly, it is considered fully that the elastic deformation can enhance the carrying capacity, and the manufacturing costs are reduced greatly.

3) The normal stiffness among contact points is regarded as the contact, and it has not been considered that the positions of different engaging points have influence on the stiffness change. The calculated results are somewhat different from the actual conditions, and the further study is required.

\section{CONFLICT OF INTEREST}

The authors confirm that this article content has no conflict of interest.

\section{ACKNOWLEDGEMENTS}

This work is supported by Anhui Province Science \& Technology Research Plan (No.07010100085) and Natural Science Fund (production, science research and teaching) of Education Department of Anhui Province (No. KJ2012A247).

\section{REFERENCES}

[1] W-J. Wang, and R-F. Li, "Assembling and kinetic simulation on a new type double-ring reducer mechanism", Mech. Res. Appl., vol. 19, pp. 116-118, Apr. 2006.

[2] Q. Xu, and Z. Y. Xu, "Analysis of meshing characteristics and assembly conditions of novel type double ring reducer", J. Mach. Design, vol. 29, pp. 67-69, Oct. 2012.

[3] X-L Shu, and Q-X. Xia, "Strength calculation for internal meshed gear with few tooth number difference", J. Mach. Design, vol. 35, pp. 35-37, Oct. 2002.

[4] X-H. Yang, "Study on real contact teeth and load distribution of internal meshed gear with few tooth number difference", Rader \& ECM, pp. 11-19, Jan. 1990.

[5] C. C. Zhu, and D. T. Qin, "Study on real contact teeth and their load distribution of a three ring reducer", Transact. Chinese Soci. Agric. Mach., vol. 31, pp. 60-63, Feb. 2000.

[6] G. C. Ying, and C. Zhang, "Elastic meshing, load distribution and strength calculation of three-ring transmission", J. Mach. Design, vol. 21, pp. 12-15, Aug. 2004.

[7] B.B. Liu, and C. Zhang, "Study of multi-tooth pairs' elastic meshing effect of internal gearing with small tooth number difference ", Mech. Sci. Technol. Aerospace Eng., vol. 26, pp. 1006-1009, Aug. 2007.

[8] T.M. Cheng, and N.Q. Wang, Machine Design, Harbin: Harbin Institute of Technology Press, 2008.

[9] D.T. Qin, and L-Y. Xie, Modern Handbook of Mechanical Design, Bejing: Chemical Industry Press, 2011.

[10] Y-C. Xie, Study on Kinetic Characteristic and its Fault Diagnois of the Double-ring Gear Reducer, Ph.D. thesis, Chongqing University, Chongqing, P.R. May 25, 2004. 